\title{
Selenium nanoparticles inhibit Staphylococcus aureus growth
}

This article was published in the following Dove Press journal:

International Journal of Nanomedicine

28 July 2011

Number of times this article has been viewed

\author{
Phong A Tran' \\ Thomas J Webster ${ }^{2}$ \\ 'Physics Department, ${ }^{2}$ School of \\ Engineering and Department of \\ Orthopedics, Brown University, \\ Providence, RI, USA
}

Correspondence: Thomas J Webster School of Engineering and Department of Orthopedics, Brown University,

Providence, RI 02912, USA

Tel +l 40| 86323 I8

Fax +I 4018639107

Email thomas_webster@brown.edu

\begin{abstract}
Staphylococcus aureus is a key bacterium commonly found in numerous infections. S. aureus infections are difficult to treat due to their biofilm formation and documented antibiotic resistance. While selenium has been used for a wide range of applications including anticancer applications, the effects of selenium nanoparticles on microorganisms remain largely unknown to date. The objective of this in vitro study was thus to examine the growth of $S$. aureus in the presence of selenium nanoparticles. Results of this study provided the first evidence of strongly inhibited growth of $S$. aureus in the presence of selenium nanoparticles after 3, 4, and 5 hours at $7.8,15.5$, and $31 \mu \mathrm{g} / \mathrm{mL}$. The percentage of live bacteria also decreased in the presence of selenium nanoparticles. Therefore, this study suggests that selenium nanoparticles may be used to effectively prevent and treat $S$. aureus infections and thus should be further studied for such applications.
\end{abstract}

Keywords: antibacterial, $S$. aureus, infection

\section{Introduction}

Staphylococcus aureus is a Gram-positive bacteria. S. aureus infection is one of the most common causes of skin infections in the US. These infections can be serious when they occur on surgical wounds, in the bloodstream, or in the lungs. Each year, there are more than 11 million outpatient/emergency room visits and 464,000 hospital admissions in the US due to $S$. aureus infections. ${ }^{1}$ S. aureus infections are complicated, as the bacterial strains have become increasingly resistant to many commonly used antibiotics. For example, a methicillin-resistant $S$. aureus infection is difficult to treat, as it is resistant to a large group of antibiotics (beta-lactams) including oxacillin, penicillin, and amoxicillin. S. aureus often infects patients at hospitals due to the patients' already weakened immune systems and procedures they undergo such as surgeries and introduction of catheters, dialysis tubes, or endotracheal tubes. For example, during insertion of an orthopedic implant, bacteria (among them, S. aureus is key) from the patient's own skin and/or mucosa enters the wound site. Bacterial infection of implants is one of the leading causes of implant failure.

Even more troublesome, bacteria can easily form biofilms when they attach to a surface. A bacterial biofilm is an aggregate of one or more types of bacteria in a hydrated polymeric matrix. ${ }^{2}$ Biofilms are a common cause of persistent infections as they are easy to form but hard to treat. $S$. aureus biofilms have been found on a wide range of medical devices including prosthetic heart valves, central venous catheters, urinary catheters, orthopedic prostheses, penile prostheses, contact lenses, endocarditis, otitis media, osteomyelitis, and sinusitis. ${ }^{3}$ Once formed, $S$. aureus biofilms are even 
more difficult to treat due to the polymeric exopolysaccharide matrix they synthesize. This polymeric matrix works as a shield to prevent drugs from penetrating inside the biofilm. Therefore, it is desirable to develop active molecules that kill $S$. aureus at very early stages of infection, thereby preventing the formation of hard-to-treat biofilms.

Along these lines, selenium has been investigated for various medical applications such as anticancer applications. Selenium as a dietary supplement has been demonstrated to reduce the risks of various types of cancers including prostate cancer, ${ }^{4,5}$ lung cancer, ${ }^{6}$ and esophageal and gastric-cardiac cancers. ${ }^{7}$ Selenium-enriched probiotics have been shown to strongly inhibit the growth of pathogenic Escherichia coli in vivo and in vitro. ${ }^{8}$ It was shown in that study that seleniumenriched probiotics (at a concentration of $0.509 \mu \mathrm{g}$ selenium per gram of probiotics) inhibited the growth of $E$. coli after 96 hours in vitro. In vivo, mice were fed with and without selenium-enriched probiotics for 28 days and then inoculated with E. coli; mortality of the treated group was the lowest. ${ }^{8}$ A series of organoselenium compounds (such as 2,4,6-tri-paramethoxyphenylselenopyrylium chloride, 9-para-chloropheny loctahydroselenoxanthene, and perhydroselenoxanthene) have been synthesized and shown to have antibacterial activities in vitro, especially against $S$. aureus. ${ }^{9-11}$ However, the effects of elemental selenium nanoparticles on microorganisms remain largely unknown.

Nanotechnology has enabled researchers to synthesize nanosized particles (that is, particles that have sizes less than $100 \mathrm{~nm}$ in at least one dimension), using them in a wide range of applications. Nanoparticles possess increased surface areas and therefore have increased interactions with biological targets (such as bacteria) compared with conventional, micronparticles. In addition, nanoparticles are much more likely to enter cells than micron particles. As a result, nanoantibacterial particles will likely exert stronger effects on bacteria than their micro-counterparts. Therefore, the objective of this study was to examine the growth of S. aureus in the presence of selenium nanoparticles. In doing so, this study revealed a new type of antibacterial selenium nanoparticle capable of decreasing S. aureus growth.

\section{Materials and methods}

\section{Synthesis of selenium nanoparticles}

Selenium nanoparticles were synthesized by the reduction of sodium selenite (Alfa Aesar, Ward Hill, MA) by glutathione (reduced form, GSH) (TCI America, Portland, OR) and stabilized by bovine serum albumin (BSA) (Sigma-Aldrich, $\mathrm{St}$ Louis, MO). Specifically, $3 \mathrm{~mL}$ of $25 \mathrm{mM} \mathrm{Na}_{2} \mathrm{SeO}_{3}, 3 \mathrm{~mL}$ of
$100 \mathrm{mM}$ GSH, and $0.15 \mathrm{~g} \mathrm{BSA}$ were added to $9 \mathrm{~mL}$ of double distilled water in a sterile cabinet. All solutions were made in a sterile environment by using a sterile cabinet and double distilled water. After mixing the reactant solution, $1 \mathrm{M} \mathrm{NaOH}$ was added to bring the $\mathrm{pH}$ of the solution to the alkaline regimen. Selenium nanoparticles were formed immediately following the addition of $\mathrm{NaOH}$ as visualized by a color change of the reactant solution from clear white to clear red. Selenium nanoparticles were then collected by centrifuging the solution at 13,000 rpm, sterilized by ultraviolet light exposure, and resuspended in sterile double distilled water five times before use in bacteria experiments.

\section{Material characterization}

The size and morphology of the selenium nanoparticles were investigated by using a transmission electron microscope (TEM). For this, the nanoparticles in deionized water were allowed to slowly dry on formvar-coated copper grids. All imaging was carried out using a Philips JOEL TEM (New York, NY) at a voltage of $80 \mathrm{kV}$.

The size distribution of selenium nanoparticles was further investigated by the dynamic light scattering (DLS) technique using a Zetasizer-Nano-S90 (Malvern Instruments, Malvern, Worcestershire, UK).

\section{Bacteria assays}

\section{S. aureus}

A bacterial cell line of biofilm-producing $S$. aureus was obtained in freeze-dried form from the American Type Culture Collection (catalog number 25923). The cells were propagated in $30 \mathrm{mg} / \mathrm{mL}$ of Tryptic soy broth (TSB) (MP Biomedicals, Solon, $\mathrm{OH})$. Once the second passage of bacteria reached its stationary phase, the second passage was frozen in one part TSB and one part 50\% glycerol (Sigma-Aldrich). All experiments were conducted from this frozen stock. One day before bacterial seeding, a sterile $10 \mu \mathrm{L}$ loop was used to withdraw bacteria from the frozen stock and streaked onto a TSB agar plate and incubated at $37^{\circ} \mathrm{C}$ for 16 hours. Bacteria from a single colony were then collected using a sterile loop and inoculated in a test tube containing $3 \mathrm{~mL}$ of TSB overnight. The test tube was agitated in an incubator at $37^{\circ} \mathrm{C}$ and shaking at $250 \mathrm{rpm}$ to achieve a bacteria solution at the exponential phase of growth. Bacteria concentration was assessed by measuring the optical density of the bacterial solution at $562 \mathrm{~nm}$ using a standard curve correlating optical densities and bacterial concentrations. A bacteria solution was prepared at a concentration of 50,000 bacteria $/ \mathrm{mL}$ for the bacteria experiments as described in the following page. 


\section{S. aureus experiments}

Three concentrations of selenium nanoparticles were tested against $S$. aureus growth: $7.8,15.5$, and $31 \mu \mathrm{g} / \mathrm{mL}$. Selenium nanoparticles were mixed with bacterial solutions and cultured for 3,4 , and 5 hours in an incubator $\left(37^{\circ} \mathrm{C}\right.$, humidified, $5 \% \mathrm{CO}_{2}$ ), shaking at $250 \mathrm{rpm}$. Bacteria cultured in TSB without selenium nanoparticles in an incubator $\left(37^{\circ} \mathrm{C}\right.$, humidified, $5 \% \mathrm{CO}_{2}$ ), shaking at $250 \mathrm{rpm}$, were used as the controls. Blank solutions were prepared by adding selenium nanoparticles into TSB without bacteria at the above particle concentrations. Blank solutions of TSB without bacteria and without selenium nanoparticles were used as the blank for controls. At the end of the prescribed time period, bacteria concentrations in the solution were determined by measuring the optical density that was then converted to bacteria concentrations using the standard curve described above. For this, $200 \mu \mathrm{L}$ of bacteria solutions, controls, or blanks were added to the wells of a 96-well plate, and optical densities were measured at $562 \mathrm{~nm}$ using a SpectraMax M5 plate reader (Molecular Devices, Sunnyvale, CA). The measured optical densities of bacterial solutions were subtracted by that of the corresponding blanks.

\section{Live/dead assays}

At the end of the prescribed time period, live/dead assays were conducted using a BacLight Bacterial Viability Kit (Invitrogen, Carlsbad, CA) following manufacturer's instructions. The fluorescence signals were measured using a SpectraMax M5 fluorescence microplate reader (Molecular Devices).

\section{Statistical analysis}

Experiments were conducted in triplicate and repeated three times unless otherwise noted. Data were collected, and the significant differences were assessed with the probability associated with one-tailed Student's $t$-tests. Statistical analyses were performed using Microsoft Excel (Redmond, WA).

\section{Results and discussion Material characterization}

TEM images of selenium nanoparticles showed that the particles were spherical and approximately $40-60 \mathrm{~nm}$ in diameter (Figure 1). Further investigation of the size distribution of the selenium nanoparticles by DLS revealed that most of the particles had hydrodynamic diameters of around $100 \mathrm{~nm}$ (Figure 2). The sizes observed by DLS were larger than those determined by TEM images because BSA molecules bound to the surface of the selenium nanoparticles created a layer that made the particles appear larger. ${ }^{12,13}$ The size-distribution profile demonstrated that the synthesis

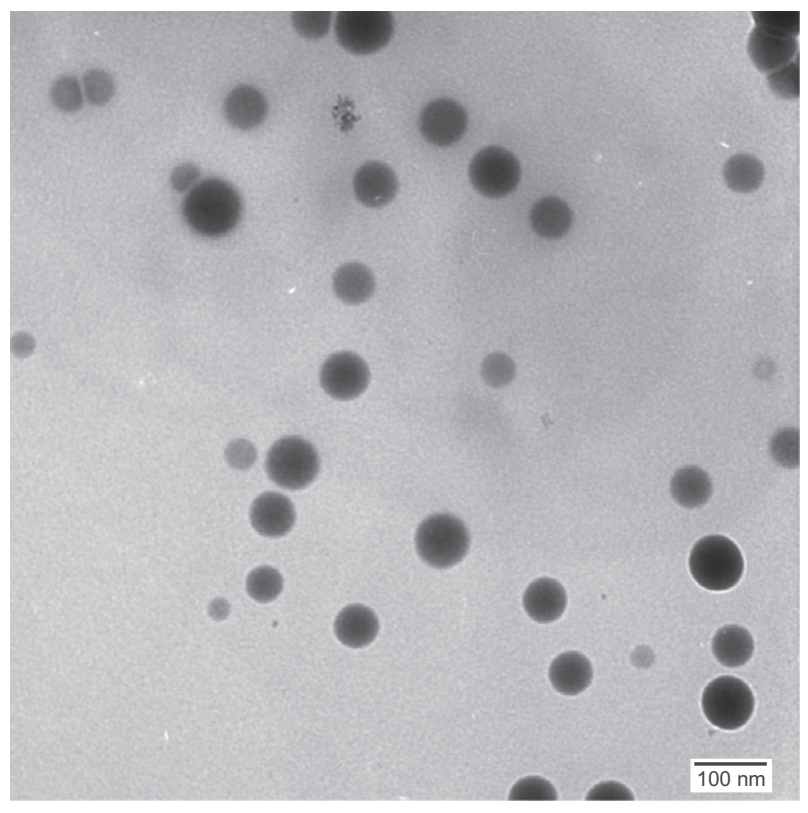

Figure I Transmission electron microscopy image of selenium nanoparticles stabilized in bovine serum albumin and dispersed in water.

method yielded selenium nanoparticles of a narrow size range stable in water. Nanoscale sizes of the synthesized selenium nanoparticles promoted a desirable large surface area important for increasing interactions with bacteria.

\section{Bacterial assays}

When the selenium nanoparticles were mixed with the bacterial solution, the growth of bacteria was inhibited after 3 hours (compared with the control, $0 \mu \mathrm{g} / \mathrm{mL}$ ). The inhibitory effects continued after 4 and 5 hours (Figures 3 and 4 ). The growth profile of bacteria in the presence of selenium nanoparticles is presented more clearly in Figure 4 (with the control not plotted). Figure 4 clearly shows a slow, inhibited growth profile of bacteria in the presence of selenium nanoparticles. Bacterial growth was inhibited approximately 20 times (compared with controls) after 3 hours, 50 times after 4 hours, and 60 times after 5 hours (Figures 3 and 4).

Live/dead assays were further conducted to determine the percentage of live bacteria in each bacterial solution. Results showed that at all the concentrations of selenium nanoparticles tested and all the time points tested (ie, 3, 4, and 5 hours), the percentage of live bacteria in the solution having selenium nanoparticles was significantly smaller than that in the solution without selenium nanoparticles (ie, controls) (Figure 5). More than $90 \%$ of bacteria in the control were alive, while only $60 \%$ of bacteria were alive in the selenium nanoparticle-treated experiments. No significant difference in the percentages of live cells was observed 


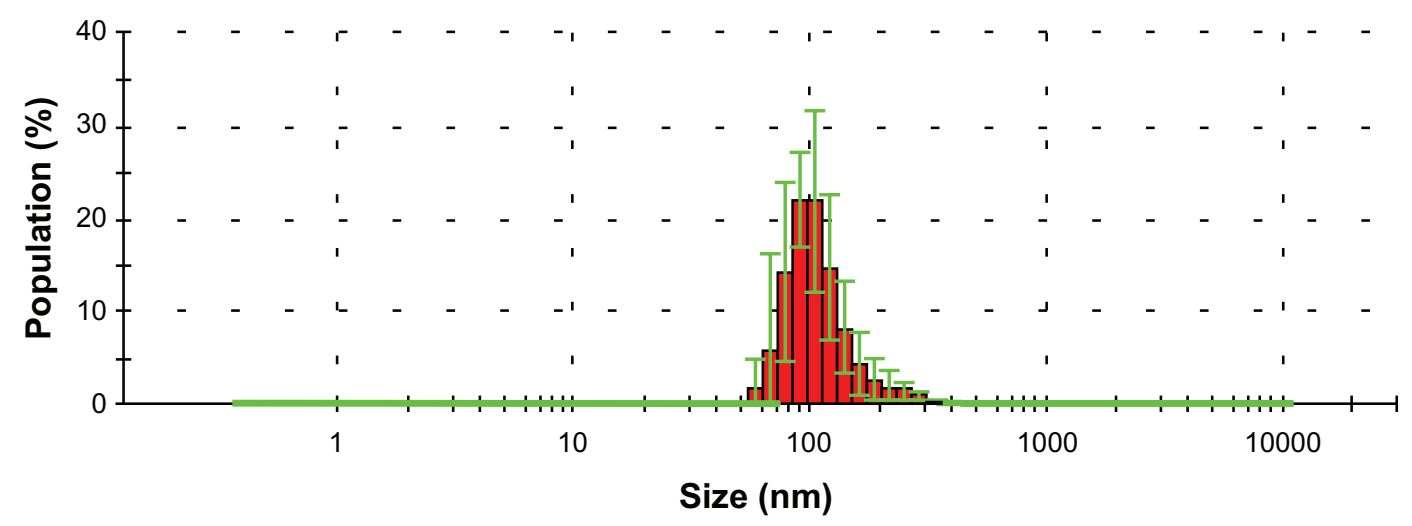

Figure 2 Hydrodynamic diameters of the synthesized selenium nanoparticles stabilized in bovine serum albumin and dispersed in deionized water. Note: Data: mean \pm standard deviation, $\mathrm{n}=\mathrm{I}$.

between the three tested concentrations of selenium nanoparticles. There was also no significant difference in the percentage of live cells between the tested time points within each concentration of selenium nanoparticles. These live/ dead results indicated that selenium nanoparticles actually killed the bacteria rather than inhibiting growth. The selenium nanoparticles also continuously killed the bacteria so that although the total number of bacteria increased slightly (or did not increase during the time period tested), the percentage of live cells remained unchanged (Figures 4 and 5).

\section{Discussion}

Nanoparticles have been increasingly studied for a wide range of medical applications. The advantages of nanoparticles include their high surface-to-volume ratios and their nanoscale sizes. The high surface areas of nanoparticles allow for more active sites for interacting with biological entities such as cells. The higher surface areas of nanoparticles compared with conventional micron-size particles also offer more sites for functionalization with other bioactive molecules, such as anticancer and antibacterial drug molecules. The nanoscale sizes of nanoparticles provide valuable properties that are not available in micron particles. For example, nanoparticles (with or without drugs attached) of sizes between 10 and $100 \mathrm{~nm}$ can penetrate tissues with tumors and can kill cancerous cells while not affecting healthy cells. This effect, called "enhanced permeation and retention," is attributed to the fact that the blood vessels in tissues with tumors have pore sizes

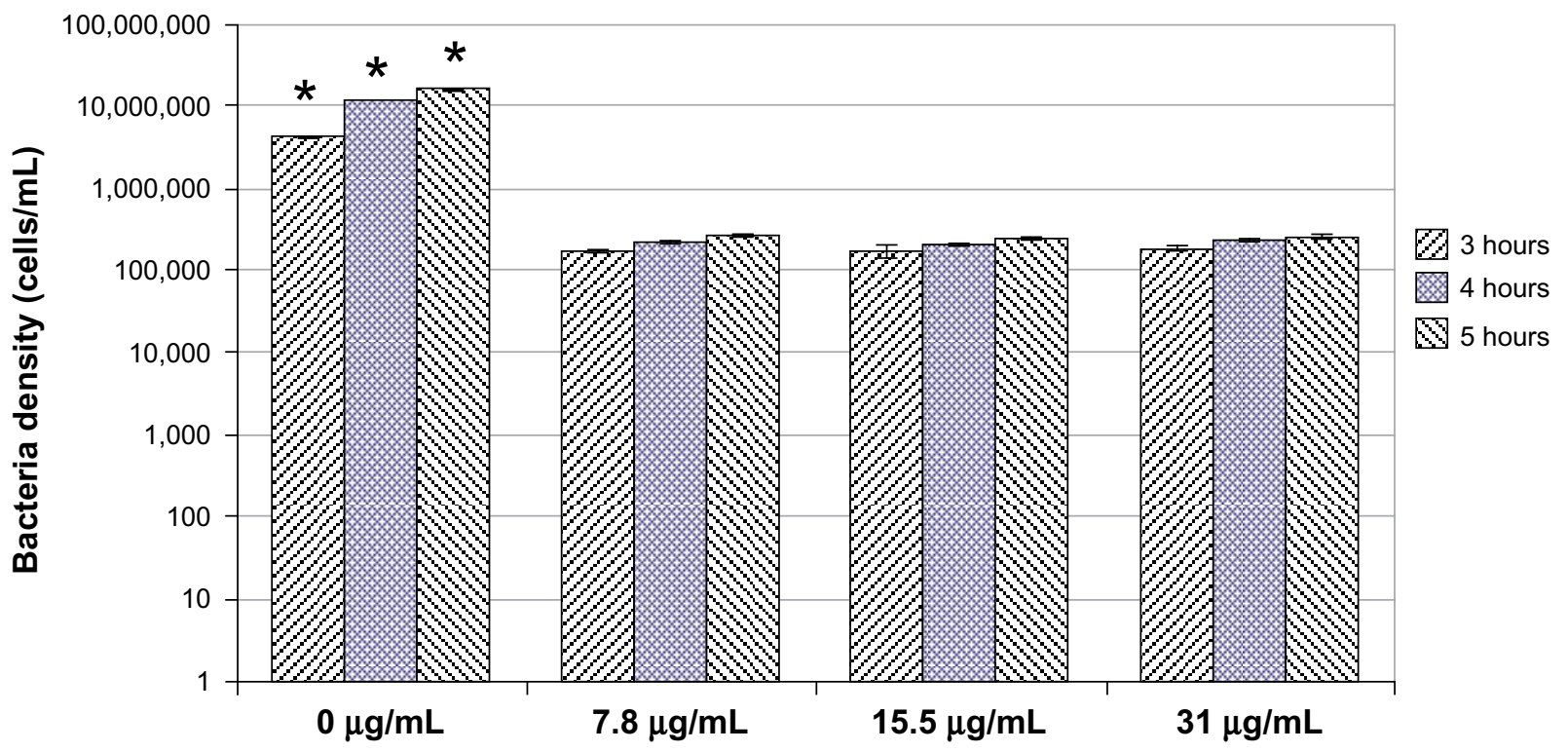

Figure 3 Inhibited growth of Staphylococcus aureus in the presence of selenium nanoparticles at all three selenium nanoparticle concentrations: 7.8 , I5.5, and 3 I $\mu g / m L$ at all tested time points $(3,4$, and 5 hours).

Notes: Data: mean \pm standard deviation, $\mathrm{n}=3$. Bacteria densities in all treated groups (ie, all concentrations of selenium nanoparticles) are significantly lower $(* P<0.01$ ) than the control group $(0 \mu \mathrm{g} / \mathrm{mL})$. 


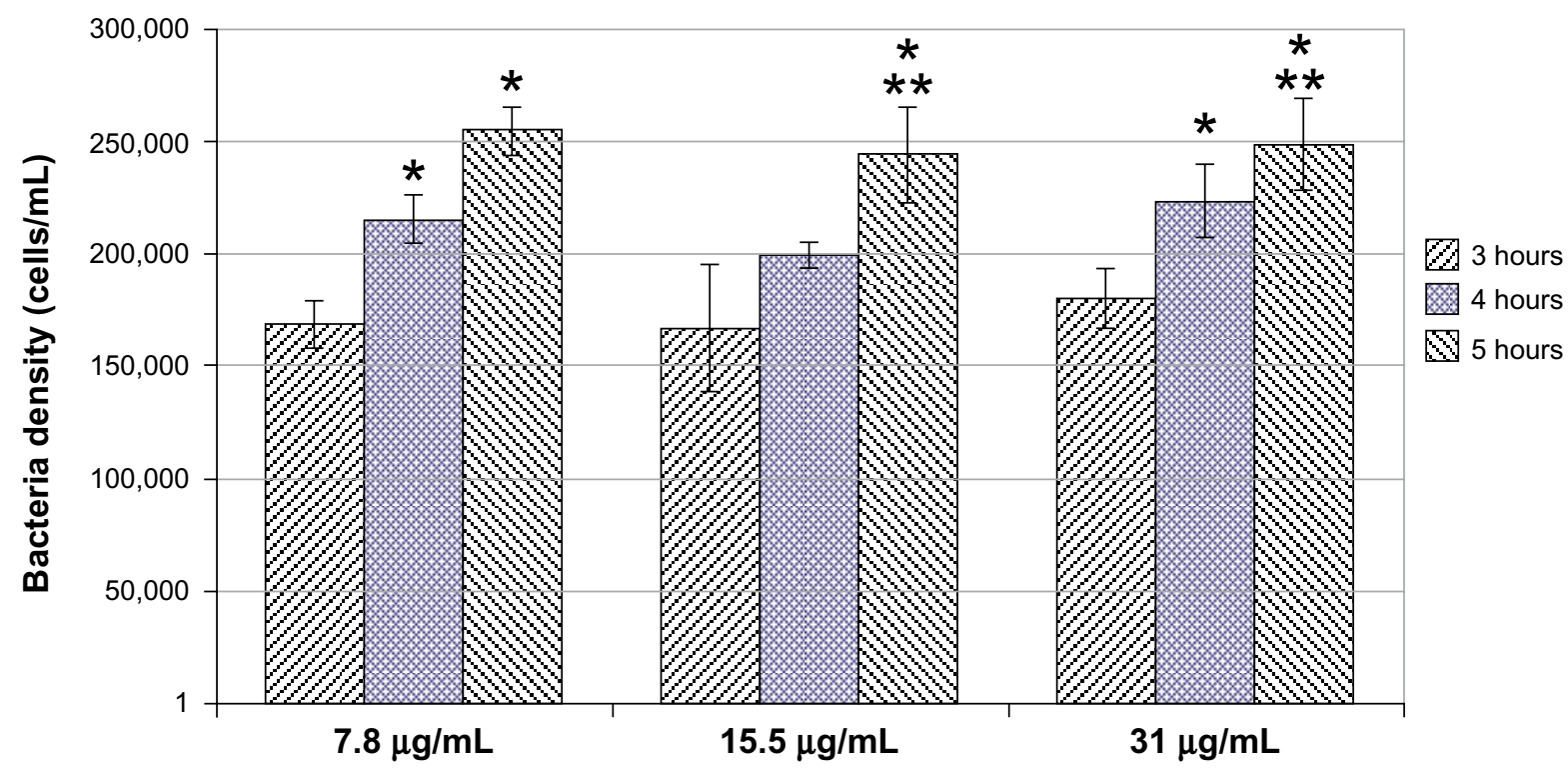

Figure 4 Growth profiles of bacteria in the presence of selenium nanoparticles.

Notes: Data $=$ mean \pm standard deviation, $\mathrm{n}=3 ; * \mathrm{p}<0.05$ compared with 3 hours (compared with the same selenium nanoparticles concentration group); $* * \mathrm{p}<0.05$ compared with 4 hours (compared with the same selenium nanoparticles concentration group). There was no significant difference in bacterial densities between different selenium nanoparticle concentrations at each time point tested. (Bacteria densities for control groups are 4,083,480, II,662,534, and I5,3I5,887 cells/mL at 3, 4, and 5 hours, respectively.)

ranging from 100 to $800 \mathrm{~nm}$, while the vessels in healthy tissues have much smaller pore sizes, from 2 to $6 \mathrm{~nm} .^{14}$

The same advantages can be used for inhibiting bacteria functions. Using nanoparticles to impede bacterial growth is an increasingly attractive approach to prevent and treat infections. Thanks to the advancement of nanotechnology, a wide range of nanoparticles (such as iron oxide nanoparticles, quantum dots, and gold nanoparticles) have been created.
However, few studies have reported that nanoparticles can effectively kill bacteria, in particular $S$. aureus. Some researchers have reported the synthesis of selenium nanoparticles and their biological effects toward mammalian cells in vitro. ${ }^{15,16}$ Others reported inhibitory effects of selenium compounds (in the form of coatings) on the growth of some types of bacteria. ${ }^{17}$ However, the influence of selenium nanoparticles on bacteria growth remains largely unexplored.

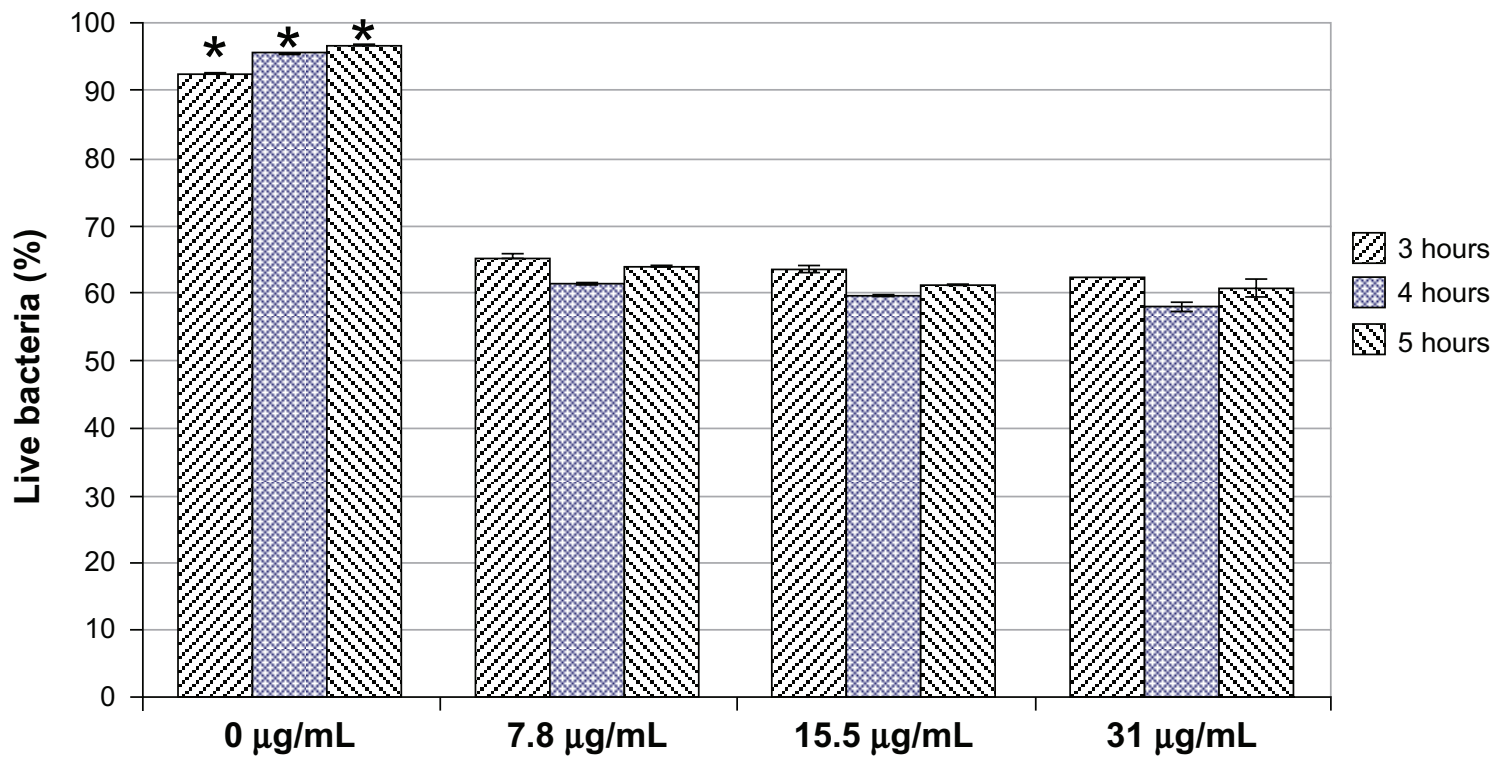

Figure 5 Decreased percentages of live bacteria in the presence of selenium nanoparticles.

Notes: Data $=$ mean \pm standard deviation, $n=3 ; * P<0.001$ compared with all selenium-treated groups at respective time points. 
This study, for the first time, showed that the novel selenium nanoparticles created here by a simple colloidal synthesis method, strongly inhibited the growth of $S$. aureus by up to 60 times compared with no treatment. This inhibitory effect of selenium nanoparticles on S. aureus at early time points (up to 5 hours) may prevent $S$. aureus from forming biofilms. In addition, results from live/dead assays implied that the selenium nanoparticles killed approximately $40 \%$ of $S$. aureus after 3, 4, and 5 hours. More in depth and longer-term studies which include sodium selenite as a positive control as well as silver nanoparticles for comparisons should be implemented to understand the working mechanisms of such antibacterial selenium properties to further develop these promising antibacterial nanoparticles.

\section{Acknowledgments}

The authors thank Kai Cheng for help with DLS data acquisition, Nhiem L Tran for help with TEM imaging, and the Herman Foundation for funding.

\section{Disclosure}

The authors report no conflicts of interest in this work.

\section{References}

1. Martinez LR, Han G, Chacko M, et al. Antimicrobial and healing efficacy of sustained release nitric oxide nanoparticles against Staphylococcus aureus skin infection. J Invest Dermatol. 2009;129(10):2463-2469.

2. Costerton JW, Stewart PS, Greenberg EP. Bacterial biofilms: a common cause of persistent infections. Science. 1999;284(5418):1318-1322.

3. Singh R, Ray P, Das A, Sharma M. Role of persisters and small-colony variants in antibiotic resistance of planktonic and biofilm-associated Staphylococcus aureus: an in vitro study. J Med Microbiol. 2009;58(8): 1067-1073.
4. Clark LC, Dalkin B, Krongrad A, et al. Decreased incidence of prostate cancer with selenium supplementation: results of a double-blind cancer prevention trial. Br J Urol. 1998;81(5):730-734.

5. Rayman MP. Selenium in cancer prevention: a review of the evidence and mechanism of action. Proc Nutr Soc. 2005;64(4):527-542.

6. Clark LC, Combs GF Jr, Turnbull BW, et al. Effects of selenium supplementation for cancer prevention in patients with carcinoma of the skin. A randomized controlled trial. Nutritional Prevention of Cancer Study Group. JAMA. 1996;276(24):1957-1963.

7. Wei WQ, Abnet CC, Qiao YL, et al. Prospective study of serum selenium concentrations and esophageal and gastric cardia cancer, heart disease, stroke, and total death. Am J Clin Nutr. 2004;79(1):80-85.

8. Yang J, Huang K, Qin S, Wu X, Zhao Z, Chen F. Antibacterial action of selenium-enriched probiotics against pathogenic Escherichia coli. Dig Dis Sci. 2009;54(2):246-254.

9. Ratushnaya EV, Kirova YI, Suchkov MA, Drevko BI, Borodulin VB. Synthesis and antibacterial activity of organoselenium compounds. Pharm Chem J. 2002;36(12):652-653.

10. Pietka-Ottlik M, Wójtowicz-Młochowska H, Kołodziejczyk K, Piasecki E, Młochowski J. New organoselenium compounds active against pathogenic bacteria, fungi and viruses. Chem Pharm Bull (Tokyo). 2008; 56(10):1423-1427.

11. Küçükbay H, Durmaz R, Orhan E, Günal S. Synthesis, antibacterial and antifungal activities of electron-rich olefins derived benzimidazole compounds. Farmaco. 2003;58(6):431-437.

12. Brouwer WM, Zsom RLJ. Polystyrene latex particle surface characteristics. Colloids Surf. 1987;24(2-3):195-208.

13. Seebergh JE, Berg JC. Evidence of a hairy layer at the surface of polystyrene latex particles. Colloids Surf A Physicochem Eng Asp. 1995; 100:139-153.

14. Tran PA, Webster TJ. Nanotechnologies for cancer diagnostics and treatment. In: Dixon CJ, Curtines OW, editors. Nanotechnology: nanofabrication, patterning, and self assembly. New York: Nova Science Publishers; 2009.

15. Zhang S-Y, Zhang J, Wang H-Y, Chen H-Y. Synthesis of selenium nanoparticles in the presence of polysaccharides. Mater Lett. 2004; 58(21):2590-2594.

16. Zhang JS, Gao XY, Zhang LD, Bao YP. Biological effects of a nano red elemental selenium. Biofactors. 2001;15(1):27-38.

17. Tran PL, Hammond AA, Mosley T, et al. An organo-selenium coating on cellulose inhibits Pseudomonas aeruginosa and staphylococcus aureus biofilm formation. Appl Environ Microbiol. 2009;75(11):3586-3592.
International Journal of Nanomedicine

\section{Publish your work in this journal}

The International Journal of Nanomedicine is an international, peerreviewed journal focusing on the application of nanotechnology in diagnostics, therapeutics, and drug delivery systems throughout the biomedical field. This journal is indexed on PubMed Central, MedLine, CAS, SciSearch ${ }^{\circledR}$, Current Contents ${ }^{\circledR} /$ Clinical Medicine, Journal

\section{Dovepress}

Citation Reports/Science Edition, EMBase, Scopus and the Elsevier Bibliographic databases. The manuscript management system is completely online and includes a very quick and fair peer-review system, which is all easy to use. Visit http://www.dovepress.com/ testimonials.php to read real quotes from published authors. 